\title{
Surfaces
}

\section{Introduction to and Discussion Summary of Wang Hui's Humanism as the Theme of Chinese Modernity}

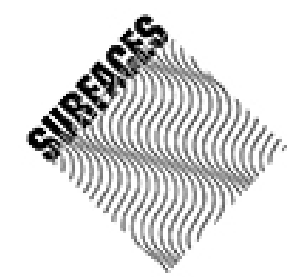

\section{J. Hillis Miller}

Volume 5, 1995

DEUXIÈME CONGRÈS INTERNATIONAL SUR LE DISCOURS HUMANISTE (1995)

SECOND INTERNATIONAL CONFERENCE ON HUMANISTIC DISCOURSE (1995)

URI : https://id.erudit.org/iderudit/1064991ar

DOI : https://doi.org/10.7202/1064991ar

Aller au sommaire du numéro

\section{Éditeur(s)}

Les Presses de l’Université de Montréal

ISSN

1188-2492 (imprimé)

1200-5320 (numérique)

Découvrir la revue

Citer ce document

Hillis Miller, J. (1995). Introduction to and Discussion Summary of Wang Hui's Humanism as the Theme of Chinese Modernity. Surfaces, 5.

https://doi.org/10.7202/1064991ar
Résumé de l'article

Dans le cadre du deuxième congrès international sur le discours humaniste, ce texte est une introduction à " L'Humanisme comme thème de la modernité chinoise " de Wang Hui, et rapporte les principaux pôles d'intérêt qui ont émergé au cours de la discussion. S’y ajoute la transcription des remarques préléminaires faites par Wang Hui au début de la session. 


\section{Introduction to and Discussion Summary of Wang Hui's}

\section{Humanism as the Theme of Chinese Modernity}

J. Hillis Miller

jhmiller@uci.edu

Department of English and Comparative Literature

Surfaces Vol.V.202.1 (v.1.0A - 31/12/1995)

Copyright for texts published in SURFACES remains the property of authors. However, any further publication should be accompanied by an acknowledgement of SURFACES as the place of initial publication.

ISSN: $1188-2492$

\section{ABSTRACT}

In the context of the Second International Conference on Humanistic Discourse, this text introduces Wang Hui's "Humanism as the Theme of Chinese Modernity" and reports on the central concerns that emerged in its discussion. It also includes the transcription of Wang Hui's preliminary remarks to the session.

\section{RÉSUMÉ}

Dans le cadre du deuxième congrès international sur le discours humaniste, ce texte est une introduction à «L'Humanisme comme thème de la modernité chinoise» de Wang Hui, et rapporte les principaux pôles d'intérêt qui ont émergé au cours de la discussion. S'y ajoute la transcription des remarques préléminaires faites par Wang Hui au début de la session.

Wang Hui's introductory oral presentation began with apparently marginal questions about translation. The title of his paper, he said, should be "Humanism as the Theme of Chinese Modernity," and wherever the translation says "humanistic discourse," it should perhaps read "discourse of humanism." The misunderstanding, he said, arises from the fact that "the 
Chinese translations of 'humanistic discourse' and 'discourse of humanism' are the same if you translate them word by word."

These apparently small details of translation go to the heart of what is at stake in Wang Hui's paper and in the discussion of it: translation in several senses of the word. The discussion of Wang Hui's paper was a fascinating demonstration of the challenges facing translation, especially translation from East Asian languages and cultures into Western ones, and vice versa. The "translation" at issue is not only translation of a given word or phrase ("humanism" or "humanistic discourse" in this case) from one language to another, but also translation in the sense of a carrying over through understanding of the complex and heterogeneous cultural contexts within which a phrase like "humanistic discourse" has meaning in one country or another. The difficulty or even aporia of such translation arises from two problems: 1) Any word, for example, any one of the Chinese words used to translate the English word "humanism," has a complex history that cannot be entirely expunged from it when it is used to translate a foreign word and its concept. 2) Attempts to explain the difficulties of translation, such as Wang Hui's paper and the extension of it in his oral presentation prior to the discussion, must themselves use further words that themselves have a complex history in the two languages, for example the word "principle" in Wang Hui's oral presentation. The attempt to clear up difficulties in translation is likely only to plunge deeper into the difficulties of translation or even into the abyss of untranslatability. This does not mean that translation does not or should not occur, but that its difficulties should not be minimized. As in the case of what Wittgenstein says about learning a language or learning how to play a game, understanding another culture requires not only long and patient study but a kind of leap within the linguistic presuppositions of the other culture that cannot easily be rationalized or accounted for. In this case, a group of distinguished scholars from Hong Kong, The Republic of China, the Peoples' Republic of China, Japan, The United States, France, and Germany engaged in an attempt to understand just what their counterparts in other countries mean by "humanism" and "humanistic discourse," as they are used both generally and as organizing terms within the university. Since the discussion was focused on Wang Hui's paper, the primary goal of the discussion was to understand these terms as they are used in the People's Republic of China.

A number of general features emerged from the discussion. They are all important aspects of cultural and intercultural history.

1. Each culture has its own complex internal historical development. This is the case both with the meaning a given term like "humanism" has from one time to another and also with the relation that term has to the evolution of classes and institutions within the surrounding cultural context. In the case of China, the modern words for humanism, renwenzhuyi, rendaozhuyi, and renbenzhuyi, each use a word, renwen, that comes from the Classic of Changes. The words have been a battleground for vigorous debates in modern China.

2. Each culture has in one way or another imported and modified for its own use both concepts and institutions from other countries. The humanism of the United States scholar Irving Babbitt was, for example, 
influential in modern China, as was the thought of John Dewey. Marxism is of course a foreign import in China, along with certain Marxist notions of humanism. The institutional structure of the Chinese Academy of Social Sciences (which includes literary study) is borrowed from Soviet models, while the present-day organization of humanistic disciplines in Chinese universities is taken from Western or Japanese universities. Certain Japanese words (along with their accompanying concepts) are adopted in Chinese, and vice versa.

3. Neither East Asia nor the West are monolithic cultures, not even those bound together by a common language. "Humanism" and "humanistic discourse" have different meanings and are institutionalized differently in Hong Kong and the Republic of China from the way that is done in the Peoples Republic of China. Present-day "cultural studies" in the United States have no exact counterpart in England or in continental Europe. "Cultural studies" mean something different on the West Coast from what they mean on the East Coast of the United States. They will no doubt be different yet again when they are adopted in the PRC, as seems now to be happening. These three forms of complexity (a constantly changing internal history ; constant borrowings from other cultures; differentiation within any given apparently unified culture) mean that the usage of "humanism" or "humanistic discourse" in various languages is an extremely complicated, dynamic, and constantly changing field.

\section{Recapitulation of the Main Points of the Discussion}

The moderator for this session, J. Hillis Miller, began by identifying some general presuppositions of Wang Hui's paper and raising some general questions about it. What is the difference between a theme and an event as Wang Hui uses those terms? When does a theme become an event? Important assumptions in the paper include the presupposition that word meanings are always historical and that they are usually "ambiguous," that is, have quite different meanings at different times and in different contexts. The Chinese words for "humanism" have been used in China at different times both to challenge Marxism and to challenge Western capitalism. Wang Hui's paper demonstrates that the question, "What is man?" has not been asked in China in the same way as it has been traditionally asked in the West. From Pico della Mirandola through Hamlet down to Sartre's "Is Existentialism a Humanism?" and Heidegger's Letter on Humanism, humanism in the West has been likely to lead to extremely problematic general questions about what distinguishes man from animals, gods, inanimate objects, and machines. This issue does not seem to arise in China, at least not in Wang Hui's paper. Instead the human is distinguished from the heavenly (that is, the physical, the cosmos) by the way "education through rites and music," cultivated knowledge of "poetry, history, rites, and music," is appropriate to the human. This is not to say that Chinese culture lacks something, only that the two cultures seem quite different on this point. 
Miller also raised the question of the right each participant in the conference has been implicitly given to "represent" a whole culture or a large segment of it. It is easy to see how this implied representative role is problematic.

Wang Hui then introduced the general discussion with an extended further discussion of "humanism" in Chinese thought from the Confucian classics to the present. His remarks constituted more or less a second section of his paper and warrant separate publication. I append them to this summary. The essential points are the following: Just as in traditional Chinese thought no sharp distinction is made between science and humanism, so that for $\mathrm{Zhu} \mathrm{Xi}$ investigating things is a way to cultivate the self, so in modern China, for example in the writings of $\mathrm{Hu} \mathrm{Shi}$, the lines between science, social science, and the humanities are by no means as sharp as they are in the West. Social science and humanistic study are both parts of science. Poetry writing and philosophy, not to speak of literary study, are by Hu Shi thought of as sciences. Science includes humanistic studies. An example is the way the Chinese Academy of Social Sciences (which includes institutes of literature) was before the Cultural Revolution a branch of the Chinese Academy of Sciences. Before the twentieth century China did not have humanistic disciplines such as literature, history, and philosophy in the Western sense. Only gradually have they adopted the Western taxonomy, but this taxonomy "restructured Chinese knowledge." Moreover, both ancient and modern Chinese thought presuppose that, to quote Wang Hui again, "all men and women of all nations at all times share a common essence. This essence is not only the essence of the human being, but also the essence of the cosmos and everything within it." That presupposition has survived the restructuring of Chinese knowledge.

William Tay began the discussion by observing that modern Chinese has sought for a vernacular through a romanization or latinization of Chinese, or even through Esperanto. Leo Lee added that the Chinese word for science is borrowed from Japanese, and observed that modern Chinese methodology in the human sciences, though influenced by Dewey and other Westerners, is still linked to Confucian methodology. Wang Hui replied that Marxism came into Chinese thought in the late 1920s and early 1930s and was combined with traditional Confucian moral thinking that gave a high value to the search for truth.

Hendrik Birus then initiated a general comparison of Western to Chinese ways of thinking about man. For the West man is above the beasts and a little lower than the angels. Humanitas in the Western Middle Ages was set against bestialitas in one direction and deitas in the other. Educated humanity was also set against barbarian ignorance. Does anything like this kind of hierarchy exist in Chinese thought? Wang Hui answered that for Chinese thought there is a difference in levels but not an opposition of principle or substance. Nature or the cosmos is a super principle that contains all these different levels. This led to a general discussion, participated in by Murray Krieger, Pauline Yu, Jacques Derrida, Leo Lee, and Ludwig Pfeiffer, as well as by Wang Hui and Hendrik Brius, of the differences between Chinese thought and the West on this and related points, for example the question of whether the "heavenly" in Chinese 
terminology is to be thought of as divine or human. The answer seemed to be that such a question is wrongly posed, since, as Wang Hui had said, in Chinese thought the unity of heaven, earth, man, all creatures, and all objects is more important than any hierarchy among them, even though the educated or enlightened man (!) is given a kind of privilege in having a moral life, as for example by Mencius.

The discussion then shifted, as Murray Krieger noted, to questions of university organization that are not the same as general questions of the role of humanistic discourses in a culture. "How institutional do we want our discussion to be?" he asked. This did not keep the discussion from focusing thereafter on institutions. Though the modern Chinese organization of the humanities by disciplines has been borrowed in part from the West, nevertheless historically the taxonomy was very different. Before 1900 there were no humanities in the Western sense in Chinese universities, no history, no philosophy as separate disciplines in the modern sense. To cite again Wang Hui's paper, according to Kong Ying-da in a comment on the Classic of Changes, "The Sage observes the human culture, that is, poetry, history, rites, and music, and uses these to educate everyone in the world." It is a long way from that to a modern university structure.

A discussion ensued of the way an idea in the United States somewhat parallel to that of the traditional Chinese education of a sage, that of a "liberal arts" education, has weakened today as the humanities have become less important in research universities, even if they have "colleges of arts and sciences." Hazard Adams observed that many traditional humanities departments, for example in the University of Washington in Seattle, have succeeded in transferring themselves to the school of social sciences. The "humanities," said Adams, are all those departments that cannot escape to the social sciences.

Adams' comment led to a lively discussion by Lee, Iser, Miller, Tay, Derrida, Adams, and Pfeiffer concerning the development of so-called "cultural studies," especially in the United States. Miller saw this as indicating a strong drift of the humanities toward the social sciences. William Tay commented that in Hong Kong American cultural studies are hard to understand, while Iser observed that nothing in Germany today parallels the development of cultural studies in the United States, and Adams noted the relative blurred borders of cultural studies in the United States as against the disciplinary definiteness in England. Derrida said there is nothing comparable in Europe to cultural studies in the United States. American cultural studies are untranslatable in Europe. Therefore they are an example of heterogeneity within the West. On the one hand, said Derrida, he would have no answer to the question, " What is cultural studies?" It is an artifact with no concept. Nor could young scholars starting a program in cultural studies at one American university he visited tell him what cultural studies are. On the other hand, he said, American cultural studies are absolutely necessary. Their rise is not to be explained simply as confusion. They are a symptom of something important happening in the world, something signalled by the breaking down of traditional clear disciplinary borders within United States universities. In confirmation of that, Miller stressed the spontaneity of the rise of cultural studies in the United States, the way it 
arose in many different sites at once in a way that can be explained by no one influence (that of Foucault, for example). The rise of cultural studies has been overdetermined. That rise is extremely impressive in the way it has enlisted so much intellectual energy and commitment.

Lin Yaofu then observed that Taiwanese universities are much more conservative than those in the PRC. Taiwanese universities remain more Confucian in spirit and use Confucian humanism as a means of resisting Western influence. Kojin Karatani spoke of the way computers in Japan have enhanced the power there to use the traditional modified Chinese characters. He predicted that the diffusion of computer use will change much in China.

Wang Hui was given the last word. He observed that the structure of the PRC university is in fact borrowed from Japan and called for more comparative study of the sort begun by this discussion. He sees the term "cultural discourse" as better than "humanistic discourse." So the discussion ended where it began, with questions of translations. It seems clear that one main mission of the ICHD will be to confront problems of translation in the extended sense involving institutions and cultural forms as, for example, these problems came up in Wang Hui's paper and the discussion of it.

\section{Wang Hui's preliminary discussion of "Humanism as the Theme of Chinese Modernity"}

I am afraid that my paper is not to the point of the conference. I was in such a hurry to write it to meet the deadline that I failed to read the papers for the last conference before I wrote my paper.

I have to correct some mistakes in translation and my own misunderstanding about the theme of humanistic discourse:

1. The title of my paper should be changed to "Humanism as a Theme of Chinese Modernity." And most of the terms for humanistic discourse should change to the "discourse of humanism." The misunderstanding arises from the fact that Chinese translations of "humanistic discourse" and "the discourse of humanism" are the same if you translate them word by word.

2. The subtitle on page 3 should change to "Inter-culture and the Three Chinese Translations of Humanism." On page 4, in the middle, the term "translingual practice" is quoted from Lydia Liu's article, "Translingual Practice: The Discourse of Individualism between China and the West", Positions, 1:1, Duke University Press, Spring 1993.

3. The third is not a correction but a subsidiary demonstration. On page 7, the second paragraph before the parenthesis, I mention that renwenxueke in Chinese universities were not the same as the humanities (or liberal arts) in Western universities. But there is a gradual process in which many subjects such as psychology, anthropology, Western philosophy, etc. were established by Chinese universities after the May Fourth period. 
Now, I am not really going to summarize my paper. I am trying to discuss the theme from another direction: what is the relationship between scientific discourse or social scientific discourse and humanistic discourse in Chinese culture? In his article "Humanistic Discourse and the Other," Professor Miller points out, "Though 'humanistic discourse' can be taken simply to designate the languages of the humanities as opposed to those of the social sciences or the natural sciences, nevertheless the word 'humanistic' implies that all men and women of all nations at all times share a common essence. This essence distinguishes them from animals or inanimate objects. They are all human beings." One of the points of my paper (p. 8) is that there was no clear distinction between social sciences and humanities for a long time in China. One of the reasons for this is that all subjects were based on the conception of base and superstructure and other Marxist concepts considered "scientific." Before the cultural revolution, even the Chinese Academy of Social Sciences was part of the Chinese Academy of Sciences.

The problem is that during the period of May Fourth some scholars in the field of philosophy, history, and literature described themselves as scientists and their approach as a scientific method. Even Hu Shi described his creation of modern poetry as a "scientific experiment." So they were humanists posing as scientists. They were from the "New Cultural Movement" and were believers in humanism. Furthermore, instead of designating the languages of the humanities separately they incorporated the language of natural science and social science into their language of humanistics. At the same time, they tried to demonstrate their humanist issues through applications of the language of science. Inevitably some scholars were described as scientists. But for me, the confusion between humanistic discourse and scientific discourse is meaningful in indicating the relationship between "nature" and "human nature" in both traditional and modern Chinese thought.

Here are two related examples. One is the great philosopher of the Song dynasty, Zhu Xi, and the other is a modern philosopher, one of the leaders of the "New Cultural Movement" in the May Fourth period. The Chinese word for science is kexue which is a 20th-century Japanese term. But before 1897, the Chinese word for science was gezhi which is the abbreviation of gewuzhivi, a very early term from one of the Chinese classics, in the daxue (Great Learning) chapter of the Liji (Book of Rites). There we find a direct relationship among the text's statements "the extension of knowledge $(z h i)$ lies in the investigation of things $(w u), "$ "after things $(w u)$ are investigated, knowledge (zhi) becomes complete," "to illuminate the luminous virtue" (ming mingde). Here $w u$ or things refers to ethical and moral behavior, $z$ hi or knowledge refers to ethical and moral knowledge. Thus, standing side by side with "rectifying the heart-mind" (zhengxin) and "making thoughts sincere" (chengyi), we find that the "investigation of things and extension of knowledge" is a means of "cultivating the self" (xiushen) and "illuminating virtue" (mingde). The purpose of the exercise is to "harmonize the family, order the state, and pacify the world." Such is the Confucian doctrine of "being an interior sage and an exterior king" (neisheng waiwang).

What gave proponents of lixue an avenue for linking gewuzhizhi as "the way of self-cultivation" to modern science was their ability to separate the notion 
from the Liji, and combine it with another concept, "probing thoroughly the principle, exhausting nature" (quiongli jinxing), taken from the "Yizhuan" (Treatises on the Book of Changes), thus not only making gewu zhizhi into an important category in the methodology of Lixue, but also endowing it to some extent with implications similar to epistemology. Zhu Xi concluded his teaching on "the investigation of things" in a related supplementary treatise in zhangju (The "Great Learning" in Chapter and Verse).

What is meant by "the extension of knowledge lies in fully comprehending the principle in things" is that if we wish to extend our knowledge to the utmost, we must probe thoroughly the principle in those things we encounter. It would seem that every man's intellect (in his heart-mind) is possessed of the capacity for knowing and that everything in the world is possessed of principle. But to the extent that principle is not yet thoroughly probed, man's knowledge is not yet fully realized. Hence, the first step of instruction in greater learning is to teach the student that whenever he encounters anything at all in the world he should build upon what is already known to him of principle and still probe further, so that he seeks to reach the limit. After exerting himself in this way for a long time, he will one day become enlightened and thoroughly understand (principle); then, the manifest and the hidden, the subtle and the obvious (crude) qualities of all things will all be known, and the mind (-and-heart), in its whole substance and vast operation, will be completely illuminated. This is called "fully comprehending the principle of things," "the completion of knowledge."

To sum up, to comprehend Zhu Xi's doctrine of "the investigation of things and the extension of knowledge," one must attend to the main points listed below. First, gewuzhizhi is the organic part of the structure of Zhu Zi's lixue. The problem that it seeks to resolve is having begot the myriad creatures with the aid of qi or "ether," how does $l i$, as the origin of the universe and the noumenon of the supreme ethical and moral principle, return to the noumenal li, so that gewu zhizhi is an indispensable link in the selfunification of $l i$, the $l i$ which is "the principle and nature without human body." Accordingly, though "the investigation of things and the extension of knowledge" is a direct expression of the process and various ways in which a person recognizes the li of each thing, obviously an inclination to knowledge in the structure of lixue is but a process of the return of the noumenal li to itself, or of the consummation of self-arrangement, self-transposition, and self-combination. This determined a priori the outcome for the process of subject-object recognition.

Second, the phrase the "investigation of things" is comprised of three aspects, that is, "to approach the things" (jiwu), "to probe thoroughly the principle" (qiongli), and "to reach the limit" (zhiji), with the second one as the core notion. Although the ultimate aim of "probing thoroughly the principle" is to grasp the "heavenly principle of the cosmos" (tianli), since Zhu Xi inherited and developed the two Cheng brothers' thought of "differentiation between principle and individuality" (li yi fenshu), which suggested that all things on earth are in differential relationship to the general and the particular, hence "the differentiation of the principle under the heaven into Myriads," the direct object of "probing thoroughly the principle" widely involves the natures and rules of concrete things. Thus, 
"probing thoroughly the principle" must employ "approaching the things" as its prerequisite, otherwise the principle will have nothing to adhere to.

Third, "the labor of investigating things as discussed by Master Zhu is still the labor of the heart-mind, or an extension of the li already known into the realm of unknown." The li already known includes filial affection and piety, compassion, rites and regulated music, the way of ordering and pacifying, as well as creatures of the universe and other physical phenomena. What is meant by "differentiation between principle and individuality" is also that since myriads of principles belong to one single principle, that principle is separable from neither matter nor the heart-mind, and that principle lies in things--all these my heart-mind is able to illuminate. At the end of Daxue zhangju, Zhu Xi insists that his supplementary treatise on gezhi "is essential for illuminating the virtue," eventually summing up the achievement of gezhi in the moral state, in which "my heart-mind, in its whole substance and vast operation, will be completely illuminated. " Thus, it is clear that gezhi is not only a way of learning, but also the fundamental method of rectifying the heart-mind, to make thoughts sincere, to illuminate the luminous virtue, and to rest in perfect goodness. In the process of gezhi, epistemology and the theory of human nature, the belief in truth and the law of value are totally united.

In such a case, how could we differentiate the "humanistic discourse" from its other, for example, scientific discourse?

In the context of modern China, one of the intellectual tasks was to establish humanities and formulate humanistic discourse within universities in China. $\mathrm{Hu}$ Shi, the doctoral candidate from Columbia University and youngest professor at Beijing University, published a book entitled The History of Chinese Philosophy and created a new subject - Chinese philosophy through the application of the category "philosophy" into Chinese thought. Here, I have no time to discuss how the Western category "philosophy" restructured ancient Chinese thought. My discussion will concentrate on how Hu Shi interpreted his efforts in the fields of philosophy, history, and literature.

The fact is Hu Shi had never thought of his work in those fields as humanistic discourse, but the scientific discourse which was taken as the base of the "New Culture." A humanist posing as a scientist, Hu was deeply convinced that the methodology of empirical science suited humanistic objects equally as well. The universal applicability of "scientific method," in fact, provided the groundwork for Hu's self-appointed role of "humanistic scientist." Indeed Hu Shi's concept of "science" was approximately the same as the notion of "methodology": he termed "science" as all kinds of studies that embodied the characteristics of modern scientific methods, like positivism, induction, and experiment, ranging from Darwin's evolutionism to Huxley's positivism, and from Dewey's pragmatism to the Chinese scholarship of Mozi, Cheng-Zhu and the Qing dynasty. Indeed, it was precisely because he equated "science" and "scientific method" that Hu was able to classify Mozi, Zhu Xi and the Qing masters of the PuXue, or the "empirical research school," as "scientists." 
$\mathrm{Hu}$ was not a scientist in the strictest sense, but a humanist who remolded his behavior according to the models of a scientist. The "scientific" nature of his human studies was determined by the fact that he saw the essence of science as the application of "scientific method" and meticulously scrutinized traditional Chinese scholarly methods as a "scientific methodology" identical in nature with modern Western scientific method. He regarded humanistic fields such as history, literature, and philology as real learning and took philosophical study for a research method of empirical science. The humanities, by their very nature, were not merely tools of aesthetics and moral education, but sciences that could even be considered models of empirical studies. Hu repeatedly claimed: "My lecture-essays in recent years seem to range haphazardly, but my purpose is simple: to stress the methods of learning and thinking. Thus these essays, be they discourses on experimentalism, textual research on fiction, or studies of the grammar of a character, can be said to be essays on methodology." In fact, Hu not only considered his work of "systematizing the national heritage" to be the application of the "scientific methodology" of "boldly making hypotheses and carefully seeking proofs," aimed at propagating the spirit and law of science, but even regarded his creation of free verse as a scientific experiment: whatever his original motive, there was indeed an interrelation between experimentalism and the title of Hu's poetry anthology, Changshi ji ( $A$ Collection of Experiments [1920]), which was regarded by the author as a demonstration of the theoretical hypothesis of "literary experimentalism." As a result, $\mathrm{Hu}$ became a scientist in the domains of literary, historical, and philosophical research. To him, the identification of a humanist as a scientist had a dual effect. First, he concealed his intention of "anti-tradition" under the banner of "scientific research and experiment," in order to sentence "all preconceived ideas" to death and to announce the value of "new culture" in the name of "science." Second, he set up an independent criterion of value for scientific research, and this stance of "truth for truth's sake" in turn provided a professional basis for the humanists who chose academic research as their career. In this stance, we sense the inner pressure of a humanist who, in the university system, assumed a profession similar to that of an natural-science researcher: he had to invest his work which has no immediate impact with a value similar to that of experimental science. But more important is the belief of his colleagues about natural science -natural science not only produces knowledge about nature, but also produces humanistic knowledge. In other words, scientific discourse denotes principles of politics, morals, and aesthetics. In 1907 another anarchistic intellectual, Wu Zhihui, suggested an anarchistic revolution through the establishment of a modern education system. Then, he asked: "Should we establish the subjects such as politics, ethics, literature, and so forth in universities? No, we only set up those subjects such as physics, chemistry, and other natural sciences, because human beings could draw on humanistic principles from study of natural sciences." In the context of modern China, natural science was taken as the slogan of the "New Culture Movement" and scientific discourse was considered as (new) cultural discourse. So, not only the word "humanistic" but also the word "scientific" implies that men and women of all nations share a common essence at all times. This essence is not only the essence of human beings, but also the essence of the cosmos and everything within it. 
The second point (on page 7): before the 20th century, China did not have the humanistic disciplines such as literature, history and philosophy. The traditional Chinese taxonomy of classics, history, philosophy, and literary works formed collections in a long history of canonization which involved the structure of political and cultural power in ancient Chinese society. This old taxonomy was gradually replaced by the new taxonomy of Western humanistic disciplines. Some content of the old taxonomy was reorganized into those humanistic disciplines, but I have to stress the fact that the new taxonomy has restructured the Chinese knowledge. For example, classics includes poetry, history, ritual-philosophy (but only Confucius and other thinkers were put into philosophy). The principles or disciplines which were used to distinguish the classics, history, philosophy, and literary works are totally different from those of Western humanistic disciplines. More important is that those categories such as philosophy are not only signifiers without their own disciplines or conceptions. If you talk about the question of philosophy, it is inevitable to talk about ontology, epistemology, subject, object, and so forth. So, the process of transposing the category of philosophy into China and establishing the discipline of philosophy in China is the process of re-canonization, re-conceptualization or re-structure of Chinese thought and culture. It is in this process that what we call now Chinese humanistic disciplines were established.

Wang Hui Institute of Literature, Beijing wang@topaz.ncicl.ac.cn 